\title{
Barbaloin: A concise report of its pharmacological and analytical aspects
}

\author{
DK Patel ${ }^{1}$, K Patel ${ }^{2}$, V Tahilyani ${ }^{3 *}$ \\ ${ }^{1}$ Department of Pharmaceutics, Institute of Technology, Banaras Hindu University, Varanasi-221005, India \\ ${ }^{2}$ G.L.A Institute of Pharmaceutical Research, Mathura, India \\ ${ }^{3}$ Sonekar College of Pharmacy, Koradi, Nagpur, India
}

\section{ARTICLE INFO}

Article history:

Received 13 February 2012

Received in revised form 23 February 2012

Accepted 2 April 2012

Available online 28 October 2012

\section{Keywords:}

Aloe vera

Analytical method

Anticancer

Antimicrobial

Antioxidant

Barbaloin

Pharmacological activity

Tissue culture

\section{ABSTRACT}

Barbaloin is C-glucoside of aloe emodin anthrone which is found in the plant name as Aloe vera is a perennial succulent (Liliaceal), also called the healing plant. Barbaloin have variety of pharmacological activity such as strong inhibitory effect on histamine release, anti-inflammatory, cathartic, antiviral, antimicrobial, anticancer, antioxidant activity and alternative for pharmaceutical or cosmetic applications. The peak amount of barbaloin was reached about $3 \mathrm{~h}$ after oral administration. Concentration of barbaloin in Aloe vera leaves was shown to depend on the leaf part, age, and position of the leaf. Young leaves contain more barbaloin compared to old one. Various researches have been done on barbaloin but still the relationship between the barbaloin and its overall effect has not been clarified. A more specific perceptive of the pharmacological activities of barbaloin is required to develop for pharmaceutical purpose. Many attempts have been made regarding its isolation, biological activity to examine their effects, and clarify their functional mechanism. This review gives a brief idea about its uses, ethnomedicinally and commercially important analytical techniques and their pharmacological activities.

\section{Introduction}

The barbaloin (10- beta -D-glucopyranosyl-1, 8-dihydroxy-3-hydroxymethyl-9(10H)-anthracenone) is considered to be the most specifc secondary phytoconstituent in Aloe species, widely distributed throughout world. One of the main characteristics of barbaloin is to gives yellow fluorescence. Barbaloin has been found to have a strong inhibitory effect on histamine release from mast cells. The inhibitory effect of barbaloin is much higher then that of a potent antiinflammatory drug, Indomethacin. This results indicate that barbaloin have differrent active sites at mast cells. The barbaloin content in different aloe species is higher in young leaves than that in older leaves of aloe species, whereas the terminal third of the leaves has the highest percentages of barbaloin[1]. Barbaloin is C-glucoside of aloe emodin anthrone, found in the outer rind of the aloe plant. It has been reported to constitute up to $30 \%$ of the aloe plants dried leaf exudates and play an important part in the defense mechanisms

\footnotetext{
*Corresponding author: Sonekar College of Pharmacy, Koradi, Nagpur, India Tel: +919960578369

against herbivores. Orally administered barbaloin is poorly absorbed but is metabolized by intestinal microflora to aloe emodin, which is readily absorbed. Barbaloin and aloe emodin are widely used for its cathartic properties and as a bittering agent in alcoholic beverages. Barbaloin demonstrates anti-inflammatory and cathartic effects in vivo. In vitro studies suggested that it has preferential toxicity to carcinoma cells and is a potent inhibitor of stellate cell transformation[2]. Barbaloin was one of the effective components, whose remarkable laxative effect was observed in rats. Some methods were developed and validated for the determination of barbaloin such as colorimetry, fluorometry and HPLC[3].

\section{Pharmacological activity of barbaloin}

The interaction with model membranes of barbaloin has been studied in order to explain their effects in biological membranes. Barbaloin showed affinity for phospholipid membranes whereas barbaloin stabilized lamellar structures. Barbaloin showed antiviral activity and may be used as a potential candidate for an alternative for antimicrobial, pharmaceutical or cosmetic applications[4]. 
Barbaloin is the main medicinal constituent of aloe vera which has antiinflammatory activity[5]. Some of the pharmacological activities of barbaloin are described here.

\subsection{Antimicrobial activity}

An orthogonal experimental design L9 (34) in glass house was conducted to investigate the effect of Glomus mossae, Azotobacter sp., rock phosphate and soil type on Aloe vera plant growth and barbaloin content. Inoculation by both Glomus mossae and Azotobacter sp. showed increase in barbaloin content. Thus dual inoculation of Aloe vera with AM fungi and Azotobacter is recommended to enhance barbaloin content in Aloe vera[6]. Inhibitory effects of herb extracts on caries-related bacteria and glucan of dental plaque in vitro was investigated and found that barbaloin had inhibitory effect on soluble glucan synthesis[7]. Barbaloin was found to inhibited the growth of Trichophyton mentagrophytes at minimum concentrations[8].

\subsection{Antioxidant and anticancer activity}

The antioxidant effect of barbaloin was investigated and found to have stronger antioxidants in preventing AAPHinduced hemolysis of erythrocytes. Barbaloin protected $\mathrm{Ca}^{2+}$-ATPase and protein sulfhydryl groups on erythrocyte membranes against oxidative attack by tBHP/hemin[9]. Effect of barbaloin on nitric oxide (NO), tumour necrosis factoralpha (TNF- alpha) and interleukin (IL-12) were investigated and found significant inhibitory potential. Activities of barbaloin could be caused by inhibition at the pretreated LPS/IFN - gamma activation event[10]. The cytotoxic activity of barbaloin was evaluated using the in vitro MTT colorimetric assay and barbaloin had shown no effect[11].

\subsection{Effect of barbaloin on bioavailability}

Aristolochic acid-II (AA-II) conjugated with bovine serum albumin (BSA) was used as an antigen for immunizing $\mathrm{BALB} / \mathrm{c}$ mice and found to have negligible cross-reactivity toward barbaloin[12]. The peak amount of barbaloin was reached about $3 \mathrm{~h}$ after oral administration of aloinoside B which was metabolized to barbaloin, isobarbaloin, and a hydroxyl metabolite by rat intestinal bacteria[13]. The cathartic activity of isobarbaloin in barbaloin-positive rats was nearly equal to that of barbaloin. Orally administered isobarbaloin decomposed to the active metabolite aloeemodin-9-anthrone. Therefore, it is considered that the mechanism underlying the cathartic effect of isobarbaloin is the same as that for barbaloin[14]. Natural glycoside such as barbaloin was studied regarding their metabolic fates and actions in relation to intestinal bacteria by using germ-free and gnotobiotic rats. Barbaloin, a laxative, was ineffective in conventional rats, but showed strong purgative action to gnotobiotic rats associated with the human intestinal bacterium Eubacterium sp. strain BAR, which is capable of transforming barbaloin to aloe-emodin anthrone. Barbaloin is also a prodrug and activated to aloe-emodin anthrone by human intestinal bacteria. Animal differences in the laxative effect of barbaloin are due to species differences in intestinal bacteria[15]. Barbaloin, the main laxative component of Aloe, is decomposed to aloe-emodin-9-anthrone in the large intestine of rats. Aloe-emodin-9-anthrone is known to cause an increase in the water content of large intestines, a causative factor of diarrhoea. From the data obatined in the study, it was determined that the cathartic effect of barbaloin was due to increased water content in the large intestine, rather than increased peristalsis[16].

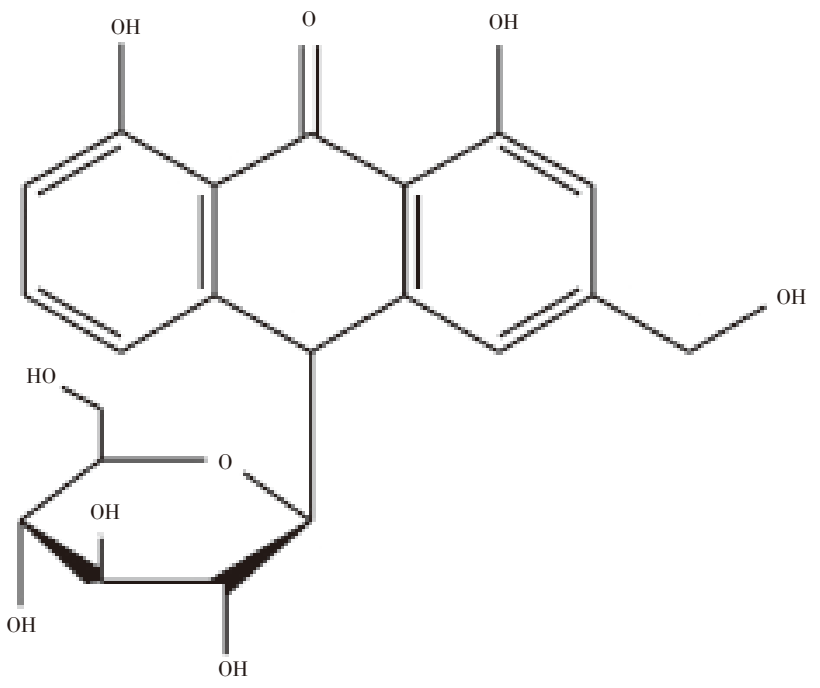

Figure 1. Chemical structure of barbaloin

\section{Effect of seasonal variation on barbaloin content}

Barbaloin, a secondary phenolic metabolite, is distributed in the plants as part of its internal defence mechanism and found to be highest in the youngest leaves. Its highest in the terminal third of the leaf, at its lowest in the basal third; higher in the terminal, adaxial, leaf margin and lower in the basal, abaxial, leaf centre[1]. The distribution of barbaloin, in Aloe arborescens leaves was shown to depend on the leaf part, age, and position of the leaf, as well as on seasonal influences[17]. Plants that are subjected to repeated leaf pruning respond by increasing the content of their secondary phenol metabolites (SPhMs). The SPhMs found in Aloe include barbaloin, aloenin and derivatives of aloeresin. Such compounds are used for many purposes, including human skin protection from sun and fire burns and high radiation, as products of the pharmaceutics and cosmetics industries, and as food supplements for treating stomach ulcers and diabetes[18]. A field study was conducted in Aloe vera with an objective to determine the effect of various levels of synthetic fertilizers on chemical constituents at the inflorescence stage of the plant. The results suggested that anhydrous barbaloin was significantly affected with application of synthetic fertilizers[19]. By frequently pruning the leaves, the content of three secondary phenolic metabolites barbaloin, aloeresin and aloenin, in the leaves can be increased dramatically. The changes in these phenolic were studied in an aqueous suspension of leaf exudate powder and in harvested leaves after storage for 
1-45 days at $4{ }^{\circ} \mathrm{C}$ in darkness. During storage in water there was rapid degradation of aloenin, but a gradual and slow degradation of barbaloin and aloeresin[20]. Hydroponically grown Aloe vera plants were treated with chlorine to determine the effects of the treatment on the growth and quality of the crop. Plant weight and shoot: root ratio decreased with increasing chlorine content. Anthraquinone and soluble protein increased, whereas barbaloin content decreased with increasing with chlorine contents[21]. Monthly variations in the concentrations of barbaloin activity of Aloe arborescens Miller were studied and correlated with temperature and rainfall. The overall concentration or activity of the components was high in the warm season and low in the cold season, and protein, saccharide, polyamines and carboxypeptidase were strongly affected by rainfall putrescine occurred in low concentrations in August[22]. Studies were conducted during 1996-97 to determine the content of barbaloin in leaves from plants of Aloe mutabilis grown in direct sunlight or shade were investigated[23].

\section{Tissue culture techniques}

An efficient micropropagation protocol has been developed using shoot apical meristem as explants in a high barbaloin content bitter cultivar of Aloe vera. BAP and IBA in combination with adenine sulphate proved optimum for shoot bud induction and increased number of shoot buds and enhanced bud proliferation. Chromosomal analysis of the regenerated plantlets established a stable germplasm with 2n=14 bimodal chromosomes[24].

\section{Analytical methods of barbaloin}

Determination of barbaloin in functional foods by high performance liquid chromatography method was developed. Kinetex C18 column and UV detector were used, whereas methanol- $0.15 \%$ glacial acetic was used as a mobile phase at a flow rate of $0.60 \mathrm{~mL} / \mathrm{min}$. This method was found to be simple, rapid, accurate and sensitive, which can be used for the determination of barbaloin in functional foods[25]. For seperation of barbaloin supercritical fluid extraction (SFE) methods was used and further analysed by high performance liquid chromatography (HPLC) using a semi-preparative column[11]. Effects of heat treatment on content of barbaloin were investigated and found that the heating promoted a remarkable decrease in barbaloin content depending on temperature and time in gel juice from Aloe vera. Barbaloin was also found unstable when it is dissolved in methanol[26]. The fluorescence quenching interaction of barbaloin, with bovine serum albumin (BSA) in $\mathrm{pH}$ 7.20 Tris-HCl buffer solution was studied. Stern-Volmer $(\mathrm{S}-\mathrm{V})$ mechanism was used for the interpretation of quenching mechanism of BSA by barbaloin. The binding constant $\mathrm{K}$ and the number of binding sites were taken as aparameter in this study. In addition, the thermodynamic functions enthalpy and entropy for the reaction were also carried out[27]. Patented hyper-dry system in combination of freeze-dry technique with micro wave and far infrared radiation was used for the preparation of Aloe vera high molecular weight fractions (AHM) which contain barbaloin as phytoconstituents[28]. A reversedphase HPLC method was developed for the quantitative analysis of barbaloin in Aloe ferox Miller and aloe-related products using C18 column with a water-methanol gradient and UV detection at $297 \mathrm{~nm}$ [29]. Estimation of barbaloin in six species of Rumex L. genus: Rumex acetosa L., Rumex acetosella L., Rumex confertus Willd., Rumex crispus L., Rumex hydrolapathum Huds. and Rumex obtusifolius L. was developed using reverse Phase High Performance Liquid Chromatography technique[30]. For the determination of low levels of barbaloin in aloe-based products, chromatography/ mass spectrometry (LC/MS) and LC with diode array detection (DAD) in the UV range (LC/UV) were developed[31]. Analytical HPLC-MS method was developed and performed for the determination of barbaloin[32]. A rapid and sensitive fluorometric method is described for the determination of barbaloin in aloe vera gum, based on complexing europium with barbaloin in a micellar solution of CTAB (cetyl trimethylammonium bromide). The complex exhibits very intense europium ion luminescence with a maximum at 613 $\mathrm{nm}$ when excited at $416 \mathrm{~nm}[33]$.

Aloe vera commonly known as the bitter aloe is a polymorphic species and found throughout world. The plant has very impresive medicinal profile which has been used since ancient times as a generic chemopreventive, antitumour and as laxative. It has important role in cosmetic formulations and food supplements and have antioxidant, antimicrobial, antiinflammatory, anticancer and antimalarial activity. Aloe vera contains barbaloin along with some other phytoconstituents mainly responsible for its pharmacological activity. It has been reported that barbaloin play an important role in the defense mechanisms of the plants. It is also used in the alcoholic beverages due to its bitter principle. An efficient micropropagation technique was developed for the production of higher barbaloin content in the tissue culture technique. So the present review described the important feature of barbaloin in regards with its uses, pharmacological activity and analytical techniques which can help researchers in the future for the development of novel therapeutic way to treat various complications. The data of the present review were collected from the available litreature sources in regards with barbaloin.

\section{Conflict of interest statement}

We declare that we have no conflict of interest.

\section{References}

[1] Gutterman Y, Chauser-Volfson E. The distribution of the phenolic metabolites barbaloin, aloeresin and aloenin as a peripheral defense strategy in the succulent leaf parts of Aloe arborescens. Biochem Syst Ecol 2000; 28: 825-838.

[2] Chang XL, Wang C, Feng Y, Liu Z. Effects of heat treatments on the stabilities of polysaccharides substances and barbaloin in gel 
juice from Aloe vera Miller. J Food Eng 2006; 75: 245-251.

[3] Jun G, Ronghua D, Xi W, Hong S, Kang L, Kaishun B. Determination of Barbaloin in Aloe vera $\mathrm{L}$. var. chinensis ( Haw. ) Berg2 er and Aloe barbadensis Miller by HPLC. Chin J Pharm Sci 2002; 11: 22-25.

[4] Alves DS, Pérez-Fons L, Estepa A, Micol V. Membrane-related effects underlying the biological activity of the anthraquinones emodin and barbaloin. Biochem Pharmacol 2004; 68: 549-561.

[5] Zhao HC, Feng RQ, Deng XG, Jin LP. Study of the Eu(III)barbaloin-CTAB system by fluorescence and determination of barbaloin. Analyt Lett 1998; 31: 819-828.

[6] Pandey DK, Banik RM, The influence of dual inoculation with Glomus mossae and Azotobacter on growth and barbaloin content of Aloe vera. Am-Eurasian J Sustain Agric 2009; 3: 703-714.

[7] Li M, Liu Z. In vitro effect of Chinese herb extracts on cariesrelated bacteria and glucan. $J$ Vet Dent 2008; 25: 236-239.

[8] Kawai K, Beppu H, Shimpo K, Chihara T, Yamamoto N, Nagatsu $\mathrm{T}$, et al. In vivo effects of Aloe arborescens Miller var. natalensis Berger (Kidachi aloe) on experimental tinea pedis in guinea-pig feet. Phytother Res 1998; 12: 178-182.

[9] Lam RYY, Woo AYH, Leung PoSing Cheng CHK. Antioxidant actions of phenolic compounds found in dietary plants on lowdensity lipoprotein and erythrocytes in vitro. J Am Coll Nutr 2007; 26: $233-242$.

[10] Vanisree M, ShihHua F, Chan Z, HsinSheng T. Modulation of activated murine peritoneal macrophages functions by emodin, aloe-emodin and barbaloin isolated from Aloe barbadensis. $J$ Food Drug Anal 2006; 14: 7-11.

[11] Kabbash A, El-Se'oud KA, Zalat E, Shoeib N, Yagi A. Supercritical carbon dioxide extraction of aloe emodin and barbaloin from Aloe vera $\mathrm{L}$. leaves and their in-vitro cytotoxic activity. Saudi Pharm J 2008; 16: 75-81.

[12] Tian M, Tanaka H, Shang MY, Karashima S, Chao Z, Wang X, et al. Production, characterization of a monoclonal antibody against aristolochic acid-II and development of its assay system. Am J Chin Med 2008; 36: 425-436.

[13] Jun G, Guogang Z, Ronghua D, Kaishun B. Isolation of aloinoside B and metabolism by rat intestinal bacteria. Pharm Biol 2004; 42 . 581-587.

[14] Ishii Y, Takino Y, Toyo'oka T, Tanizawa H. Studies of aloe. VI. Cathartic effect of isobarbaloin. Biol Pharm Bull 1998; 21: 1226-1227.

[15] Kobashi K, Akao T. Relation of intestinal bacteria to pharmacological effects of glycosides. Biosci Microflora 1997; 16: $1-7$.

[16] Ishii Y, Tanizawa H, Takino Y. Studies of aloe. IV. Mechanism of cathartic effect. Biol Pharmaceut Bull 1994; 17: 495-497.

[17] Chauser-Volfson E, Gutterman Y. The barbaloin content and distribution in Aloe arborescens leaves according to the leaf part, age, position, and season. Israel J Plant Sci 1996; 44: 289-296.

[18] Gutterman Y, Chauser-Volfson E. The content of secondary phenol metabolites in pruned leaves of Aloe arborescens, a comparison between two methods: leaf exudates and leaf water extract. J Nat Med 2008; 62: 430-435.

[19] Saradhi VSP, Salma Khanam Shivananda BG, Kumar TV, Shivananda TN. Effect of NPK fertilizers on chemical constituents of Aloe vera leaves. J Nat Remedies 2007; 7: 258-262.

[20] Gutterman Y, Chauser-Volfson E. Changes in secondary phenolic metabolites during storage as an aqueous suspension in comparison with the content in harvested Aloe arborescens leaves. Int J Food Sci Tech 2006; 41: 662-666.

[21] JiDong W, QingSong W, ZhaoPu L, Ling L, FengZhi P. Effects of exogenous chlorine on the growth and quality of Aloe vera seedlings. Acta Botanica Boreali-Occidentalia Sinica 2006; 26: 1201-1205.

[22] Beppu H, Kawai K, Shimpo K, Chihara T, Tamai I, Ida C, et al. Studies on the components of Aloe arborescens from Japan monthly variation and differences due to part and position of the leaf. Biochem Syst Ecol 2004; 32: 783-795.

[23] Chauser-Volfson E, Gutterman Y. Content and distribution of anthrone C-glycosides in the South African arid plant species Aloe mutabilis growing in direct sunlight and in shade in the Negev Desert of Israel. J Arid Environ 1998; 40: 441-451.

[24] Das A, Mukherjee P, Jha TB. High frequency micropropagation of Aloe vera L. Burm. f. as a low cost option towards commercialization. J Plant Tissue Culture Biotechnol 2010; 20: 29-35.

[25] Yang J, ChengJun S. Simultaneous determination of chlorogenic acid, resveratrol, puerarin and barbaloin in functional foods by high performance liquid chromatography. Modern Preventive Medicine 2010; 37: 4296-8.

[26] XiuLian C, ChangHai W, YongMei F, ZhaoPu L. Effects of heat treatments on the stabilities of polysaccharides substances and barbaloin in gel juice from Aloe vera Miller. J Food Eng 2006; 75: $245-251$.

[27] Tian J, Liu J, Zhang J, Hu Z, Chen X. Fluorescence studies on the interactions of barbaloin with bovine serum albumin. Chem Pharm Bull 2003; 51: 579-582.

[28] Yagi A, Hegazy S, Kabbash A, Abd-El Wahab E. Possible hypoglycemic effect of Aloe vera L. high molecular weight fractions on type 2 diabetic patients. Saudi Pharm J 2009; 17: 210-218.

[29] Zahn M, Thao Trinh Jeong MJL, Wang DS, Abeysinghe P, Jia Q, Ma WW. A reversed-phase high-performance liquid chromatographic method for the determination of aloesin, aloeresin a and anthraquinone in Aloe ferox. Phytochem Anal 2008; 19: $122-126$

[30] Wegiera M, Smolarz HD, Wianowska D, Dawidowicz AL. Anthracene derivatives in some species of Rumex L. genus. Acta Soc Bot Pol 2007; 76: 103-108.

[31] ElSohly MA, Gul W, Avula B, Khan IA. Determination of the anthraquinones aloe-emodin and aloin-A by liquid chromatography with mass spectrometric and diode array detection. J AOAC Int 2007; 90: 28-42.

[32] Rebecca W, Kayser O, Hagels H, Zessin KH, Madundo M, Gamba N. The phytochemical profile and identification of main phenolic compounds from the leaf exudate of Aloe secundiflora by high-performance liquid chromatography-mass spectroscopy. Phytochem Anal 2003. 14: 2, 83-86.

[33] HuiChun Z, RuiQin F, XiaoGuang D, LinPei J. Study of the Eu(III)barbaloin-СТАВ system by fluorescence and determination of barbaloin. Anal Lett 1998; 31: 819-28. 